\title{
Architectural Pre-Script
}

Annie Ring, Henriette Steiner and Kristin Veel

Man is no longer man enclosed, but man in debt
(Gilles Deleuze: 'Postscript on the Societies of Control')

Some of the most radical changes to the globalizing world are being written, not in the language of law and diplomacy, but in these spatial, infrastructural technologies

(Keller Easterling: Extrastatecraft: The Power of Infrastructure Space)

This book makes a critical intervention into the relationship between architecture and control at the turn of the twentieth to the twenty-first centuries. Its chapters trace how various kinds of architecture offer complex and often contradictory vehicles for establishing control. They also observe how certain kinds of architecture and infrastructure can allow for alternative modes of control to arise as well as forms of resistance. As a book about architecture and control in the present day, this is also inevitably a book about the virtual architectures of digital infrastructures and other technologies. As such, this book, the first in the series Architectural Intelligences, addresses familiar questions that lie at the intersection of architectural and cultural theory: how does the built environment condition the lives we lead? Which possibilities for living and communicating with one another do our surrounding architectures endow upon us? How may this interplay between conditions and possibilities be seen to restrict our potential for individual and collective experience in the present day? And ultimately, in what ways might such interplay through architecture and other kinds of designed structure be seen to (at times in spite of themselves) foster the emergence of the unforeseen, the uncontrolled - or the otherwise-controlled - in today's diverse and shifting present?

The perspectives presented in the coming chapters stem from academic disciplines as diverse as architecture, critical theory, and film studies, and they intersect with concerns rooted in architectural, artistic, and political practice. Together the authors writing here argue that, despite the apparently fixed nature of the built environment, despite what we might term the architectures of control in our apparently ever-controlled present, a dynamic of change is nonetheless identifiable. We see this change in the emerging spatial designs and constructions and indeed in the less tangible but no less powerful infrastructural and digital designs that are so crucial to contemporary design and living. These latter infrastructures, we contend here, are beginning to compose alternative frameworks for responses to control, including articulations of more critical or playful modes of control, in the new millennium.

These new articulations are tracked by the writers in this volume, who consider in turn factory design, military occupation, performative probings of privacy, theatre and film productions, and computational structures. As many of the essays featured in this book demonstrate, the dynamics of change in current architectures of public life make their mark on the built fabric of cities as well as on the processes of more private, everyday life that are shaped by the new technologies of digital culture. Importantly, the book demonstrates how these changes are being negotiated in aesthetic form in the most recent works of literature, 
artistic practice, and visual culture. The book thus highlights forms of resistance that may be found within both practical and imaginary responses to control that are made possible by art, film, and indeed architecture itself. We are interested, in this sense, in both aesthetic representations and existing examples of architecture and digital construction. When brought together by the aesthetic imagination, architecture in its tangible and intangible forms can be reinterpreted in terms of its relationship to control, a control that may be wielded by various agents who have a stake in it, and crucially not only those who are in established positions of power.

The discussions in this book began at the conference Changing Cultures of (In)Visibility, hosted by the editors at University of Cambridge in December 2013. In line with the original theme of that event, one of the elements that unites the various agents of control represented in the following chapters is that of vision. In recognition of the predominance of vision in the encounter with contemporary architectures, both built and digital, many of the investigations in this volume are guided by an engagement with visual studies. This bears witness to the importance of seeing in the nexus between architectures of control and more resistant infrastructures. Our aim here is thus partially to assess the stakes of seeing, an act that can never be neutral but is instead unevenly distributed, depending on the position of a subject within a given spatial configuration. As will become clear, processes of seeing and being seen no longer occur merely between the observer and the observed. We are instead dealing with a complex process of exchange, one conditioned by physical, social, psychical and infrastructural settings and one which, in its very conditioning, is capable of creating possibilities for agency, whether of a visible or invisible kind. Thus, by bringing together its variety of disciplinary viewpoints, this book deepens our understanding of the ways in which new processes of seeing, being seen, and hiding from view will necessarily change contemporary conceptions of architecture and control.

Even more crucial than vision within the contributions, however, is the concept of change. As the essays in this volume reveal, changes in the relationship between that which is considered visible and that which is considered hidden can be observed across many presentday architectural and infrastructural cultures. As they turn their attention to the structural and spatial symptoms of transformation in the contemporary moment, our writers thus pose essential questions for assessing the consequences of the forms and structures that our era sets out to build. Namely: which forms of change are desirable in contemporary systems of control and resistance, and for whom? Which structures of late modernity might - for instance through radical design forms or digital innovation - represent progressive modes of control in the hands of newly empowered agents?

\section{Structure}

With these questions at the fore, the book moves through three topics across its thirteen chapters: SURFACE PHENOMENA OF THE BROAD PRESENT, CONTESTED SITES, and CONTROL AND RESISTANCE.

In the first section, SURFACE PHENOMENA OF THE BROAD PRESENT, Alexander Galloway's chapter on the use of computational aesthetics in contemporary architecture investigates the role of the function as both a mathematical and architectural component, 
paying particular attention to the function's most exemplary representation in architecture: the black box. Through his reading of the black box, Galloway locates a form of architecture that is in constant tension with itself, exhibiting a high level of ambivalence as it both conceals and uncovers its own computational sources. Natalie Koerner's chapter then offers a study of several artistic chronotopes in order to argue for the powerful effect of place on the experience of time. This chapter demonstrates how great an influence - even how great a control - place is capable of exerting over temporal realities. However, resistant to this are temporal practices, which Koerner terms unknowing, the production of an alternative image, for instance through polka dotting, through the use of light in filmmaking to highlight the passage of time, or through the production of urban images that insist on their own placelessness. The third chapter in this section, by Rafael Dernbach, turns its attention to the concept of control as the regulation of capacities par excellence. Rafael traces an architecture of the uncanniest phenomena of our time: the surveillance that is, in common with its subjects, always, paralysingly, awake. The system Dernbach observes is one that can anticipate every deviation, including that of resistance. Is there room for agency in this context? Perhaps so, given the unexpected interplay between aesthetic surface and political depth in Lorna Muir's reading, in the subsequent chapter, of Tinker, Tailor, Soldier, Spy and Skyfall. Muir approaches these mainstream feature films only to turn their concepts on their heads, recuperating mise-en-scène as crucial to a film analysis that encompasses not only the (as Muir argues) still discipline-dominant modes of the twentieth century's surveillance societies but also the control-dominant modes of later modern societies as analysed by Gilles Deleuze and other theorists.

In the book's second section, CONTESTED SITES, Runa Johannessen expands on the terms introduced in the first section in order to propose that land is governed in the Occupied Territories of the West Bank, Gaza Strip and East Jerusalem by means of architectures of control. Johannessen introduces the crucial concept of the uncertain in current architectures of control and suppression, arguing that these are also constitutively architectures of uncertainty, in that they work only by keeping their inhabitants in states of unknowing, a term which echoes Koerner's analysis in the previous section albeit with greater pessimism considering the agency at stake here. And yet, the unplanning that interrupts practices of daily life in the Occupied Territories is counterposed by a set of strategies that Johannessen analyses in terms of the Ancient Greek concept of métis. Métis, or cunning intelligence, is used here to describe the strategies through which the people whose right to a home is officially excluded nevertheless construct a degree of affirmation that they can remain on their contested home ground. In the next chapter, Samantha Martin-McAuliffe investigates the nationwide topography of concrete bunkers in Albania as remnants of Enver Hoxha's regime (1908-1985), reading these as a sign of the dictator's behaviour that oscillated between paranoia and megalomania. Martin-McAuliffe observes how these concrete structures today take on peculiar everyday uses, such as providing shelter for animals. In this chapter, Albania's bunkerisation becomes a point of departure for investigating how architecture participated in the drama of human anxiety and suspicion in the second half of the twentieth century, displaying a strange and often inverted relationship between architecture and control insofar as the relationship between inner and outer, citizen and enemy was arguably turned upside down. Next, Michael Krause's chapter, based on a 
collaboration with videographer and academic Henrietta Williams, concerns surveillance art and the securitisation of city space in a British context. Surveillance, as Krause shows, works differently in controlling the subject than does the built environment proper. Taking this difference as an opportunity, Krause seeks a strategic multiplication of surveillance gazes through works of art made in the exceptionally high-surveillance context of today's UK, drawing conclusions relevant to global contexts of surveillance. Lastly, Maria Finn's artist essay grapples with the ephemerality of an old factory site, which she calls an undefined urban landscape in Malmö, Sweden. She zooms in on the site through four different media: photography, the map, the written word and drawing, which together offer four distinct means of capturing how this particular site negotiates the space between architecture and control. It thus concludes the section on CONTESTED SITES and provides a bridge into the final section of this volume, on CONTROL AND RESISTANCE.

This third section opens with a chapter by Joey Whitfield, tracing the theatricalisation of penality in contemporary Latin America, in a manner challenging Michel Foucault's predictions that punishment would disappear from public view with the advent of more modern forms of governmentality. Whitfield's reading of two works by Brazilian director José Padilha - a documentary, Ônibus 174 (Bus 174), and a feature film, Tropa de Elite (Elite Squad)-demonstrates that the prison has lost its hegemony as the central means of punishment, but this does not mean that punishment is now invisible. Instead, the prison has been replaced by speedier and deadlier practices, which represent a particularly chilling version of what Deleuze termed the societies of control. Is there space for resistance in this context? The second chapter in this section, by Anne Sejten, also turns to works of contemporary culture to explore the place of control and, to some degree, of resistance by considering the 'movement' and 'stasis' that define Sophie Calle's visual artworks. As Sejten shows, Calle's participatory critique - her concurrent postures of criticism and performative assimilation - is enabled by a complex dispositif of selecting, recollecting, and mapping the affective movements of the figures featured in her powerful art oeuvre. Sejten's focus on a spatial mode of mapping reveals Calle's works as fostering creative lines of flight, a refreshing possibility from within environments that can otherwise seem difficult to contest.

Following this focus on mapping as a critical strategy, Mikkel Bolt's chapter returns us to built architecture, as he analyses Zaha Hadid's design for the BMW factory in Leipzig. Bolt emphasises the importance of the container as a structure that connects neoliberal economics with the changes to labour logistics that have taken place over the past four decades and that have heralded the dominance of just-in-time production. Bolt claims Hadid's BMW as an example of Reklamarchitektur, that early-twentieth century phenomenon in which architecture functioned as a form for a mass communication, now re-emergent as communicating the urban restructuring taking place within contemporary capitalism. In this sense, Bolt argues that contemporary architecture is guilty of complicity in current modes of production, taking the powerful example of Hadid's circular-plan building, which facilitates workers' engagement in a "sophisticated self-control" by containing them in buildings that to some degree always control them. In the final chapter of the volume, philosopher and Member of Parliament in Spain (Podemos) Pablo Bustinduy argues for the limit as the place at which autonomy is constantly at stake - at stake and therefore also possible. Bustinduy's chapter draws upon the thought of Hannah Arendt, Martin Heidegger, and Karl Jaspers to 
trace the contemporary margins and horizons that might take the form of containment but can also be imagined as points of departure, temporal and spatial sites of orientation at which the futures of control, of action, and of collective understanding remain productively undecided.

The arguments worked through in all three sections of the book are considered in Hans-Ulrich Gumbrecht's 'Critical Postscript', which closes the volume by posing the question of how to approach architecture and control today at a time when, he argues, the ontological and existential status of what he terms 'space' as a category is shifting fundamentally. As Gumbrecht states, the contributions in this book all take up this difficult challenge in different ways. Gumbrecht thus identifies a productive paradox embedded in the book's premise: namely that the invisibilities of today's shifting conditions for architecture and control are hard to grasp hold of without shifting them into a potentially stifling visibility. However, as becomes clear in the rest of the book, the authors' diverse and often contrasting methodologies, theories, case studies and chosen media of representation come together here in a vital and inevitably difficult but always productive co-negotiation of how to think critically about architecture, its construction and constructive powers, and indeed how to theorise the most contemporary issues of power, agency and control.

\section{Beyond the Postscript}

As the chapters in this book turn their attention to their multiple architectures and infrastructures, the terminology of control on which much of cultural theory and of the social sciences rely is rendered ambiguous. Control forms a focus for many of the chapters in the present volume. As might be expected, a common source of reference is the French philosopher Gilles Deleuze's seminal 'Postscript on the Societies of Control' of 1992. Deleuze argues that control emerged as a paradigm divergent from the strict architectures of discipline about which Foucault had written in the middle of his career. For Deleuze, control is not defined by the utter subjection of the individual within the gridded corridors of a panoptic institution. In the (Western) societies of Discipline that Michel Foucault had analysed as coming to the fore over the course of the nineteenth century, institutions of power had distinct physical and architecturally recognisable settings, in which the panoptic principle of a centralised gaze could be easily implemented. In later modernities, Deleuze argues, power works in a fashion that is altogether less tangible: it is characterised not by the rigid "moulds" of institutions such as the prison or asylum but instead by what he calls "modulations" (Deleuze, Gilles. "Postscript on the Societies of Control". October, 59 (1992). 3-7 (p. 4)), slippery forms that can enact a shifting process of exertion and release that ensnares the subject, which in this context becomes an isolated "dividual" rather than (modernity's optimistic fantasy) an individual, or subject (ibid). Deleuze's essay is a productive starting point for considering architectures of control, both those that take built form and those that exist in the digitally-formed present, the infrastructural technologies underlying our contemporary lifeworlds. In line with their virtual, ungraspable form, these latter digital architectures exert control not through clear demarcation but instead are always in flux and as such operate through modes of constant transformation.

The fact that so many of the chapters in this volume turn to Deleuze's short text speaks volumes about its impact in cultural studies, and how seminal it has become. 
Deleuze's essay was published long before the information-intensive mixed-reality smart cities in which many people around the globe now live had emerged. Curiously, however, the essay maintains its relevance and seems almost eerily accurate in its account of how our societies have developed technologically in the quarter of a century that has passed since its writing. Admittedly, convincing arguments can be made that the disciplinary governance techniques identified by Foucault have not been replaced but continue to exist side by side with the logic of the neoliberal modular subject that constantly optimises itself. The aim of this book though - and a guiding principle for the composition of the selected essays - is to grapple with the conditions that Deleuze could neither predict nor pre-empt in 1992.

In Deleuze's Postscript, control functions by way of a fluidity that has enabled the favoured subject of neoliberal governmentality to navigate routes of trade and communication that are not concrete but more often than not as ephemeral as the digital technology that underpins much of the architecture of the present. While none of the chapters in this volume would advocate the building of new social architectures that lack any kind of control, in the sense for instance of access to high-speed internet or even to trains running reliably and on time, we may ask whether architectures of control can coexist alongside possibilities for collective life forms which are not co-opted as forces of oppression. This gives rise to a series of pertinent questions: does social participation always function in line with control? And if not, where does resistance reside? Is it only in aesthetic representation, or can it also be enfolded within the forms of digital infrastructure and built architecture themselves? This latter concern, in turn, raises further questions: is it desirable to exist outside of control? How can we understand collective organisation without including some element of control? In order to reframe this as a question of a vacillating movement between architecture's ability (whether built or digital) to set and condition as well as to provide possibilities for human social life, we may ask whether control, understood as rules and frameworks, can also become a generator for aesthetic productivity and thus for reflection and knowledge.

It is our intention that the present volume should provide a first set of urgently needed responses to these questions, doing so through its assessment of the development of new responses to control in the broad present. At times in philosophical terms and at others through concrete readings of primary texts and objects, the authors of the following chapters assess the spatial and structural formations - the architectures - that the most contemporary modes of control have come to take. Moreover, taking neoliberalism recalcitrantly at its word, the most hopeful moments in the chapters assert the potential for liberation. They mark a fluidity of movement that cannot fully be controlled by the infrastructures emerging in the twenty-first century as challenges even to the more flexible forms of governmentality envisaged by Deleuze, Foucault and others. Thus a central theme of this work is a negotiation of the possibilities that exist for coming to terms with contemporary culture's impact on the concrete physical context, what may formerly have been termed 'nature', the 'environment' or even the 'material world', and which should now be considered in an even more farreaching way a part of human culture. 
We would like to thank Masja Horn at Brill for her support throughout the process, Charlotte Johanne Fabricius and Adam Grydehøj for their meticulous help with copy editing and proofreading, and the Danish Council for Independent Research for supporting this initiative. 